\title{
Estimated hospital costs associated with preventable health care-associated infections if health care antiseptic products were unavailable
}

This article was published in the following Dove Press journal:

ClinicoEconomics and Outcomes Research

13 May 2016

Number of times this article has been viewed

Jordana K Schmier

Carolyn K Hulme-Lowe'

Svetlana Semenova ${ }^{2}$

Juergen A Klenk ${ }^{3}$

Paul C DeLeo ${ }^{4}$

Richard Sedlak ${ }^{5}$

Pete A Carlson ${ }^{6}$

'Health Sciences, Exponent, Inc., Alexandria, VA, ${ }^{2}$ EcoSciences,

Exponent, Inc., Maynard, MA, ${ }^{3} \mathrm{Health}$ Sciences, Exponent, Inc., Alexandria, VA, ${ }^{4}$ Environmental Safety, ${ }^{5}$ Technical and International Affairs, American Cleaning Institute, Washington, DC, ${ }^{6}$ Regulatory Affairs, Ecolab, Saint Paul, MN, USA
Correspondence: Jordana K Schmier Health Sciences, Exponent, Inc., 1800 Diagonal Road, Suite 500,

Alexandria, VA 22314, USA

$\mathrm{Tel}+\mid$ 57| 227724 |

Fax + I 57I 2277299

Email jschmier@exponent.com
Objectives: Health care-associated infections (HAIs) pose a significant health care and cost burden. This study estimates annual HAI hospital costs in the US avoided through use of health care antiseptics (health care personnel hand washes and rubs; surgical hand scrubs and rubs; patient preoperative and preinjection skin preparations).

Methods: A spreadsheet model was developed with base case inputs derived from the published literature, supplemented with assumptions when data were insufficient. Five HAIs of interest were identified: catheter-associated urinary tract infections, central line-associated bloodstream infections, gastrointestinal infections caused by Clostridium difficile, hospital- or ventilatorassociated pneumonia, and surgical site infections. A national estimate of the annual potential lost benefits from elimination of these products is calculated based on the number of HAIs, the proportion of HAIs that are preventable, the proportion of preventable HAIs associated with health care antiseptics, and HAI hospital costs. The model is designed to be user friendly and to allow assumptions about prevention across all infections to vary or stay the same. Sensitivity analyses provide low- and high-end estimates of costs avoided.

Results: Low- and high-end estimates of national, annual HAIs in hospitals avoided through use of health care antiseptics are 12,100 and 223,000, respectively, with associated hospital costs avoided of US\$142 million and US $\$ 4.25$ billion, respectively.

Conclusion: The model presents a novel approach to estimating the economic impact of health care antiseptic use for HAI avoidance, with the ability to vary model parameters to reflect specific scenarios. While not all HAIs are avoidable, removing or limiting access to an effective preventive tool would have a substantial impact on patient well-being and infection costs. HAI avoidance through use of health care antiseptics has a demonstrable and substantial impact on health care expenditures; the costs here are exclusive of administrative penalties or long-term outcomes for patients and caregivers such as lost productivity or indirect costs.

Keywords: anti-infective agents, topical, costs and cost analysis, hospital infections, antiseptic agents

\section{Introduction}

Health care-associated infections (HAIs), which the Centers for Disease Control and Prevention (CDC) estimates occur in one of every 25 acute care hospitalizations, ${ }^{1}$ are of paramount interest in the US. HAIs in hospitals tracked by the $\mathrm{CDC}^{1}$ include central line-associated bloodstream infections (CLABSIs), catheter-associated urinary tract infections (CAUTIs), surgical site infections (SSIs), hospital-acquired pneumonia (HAP), including ventilator-associated pneumonia (VAP), and gastrointestinal infections caused by Clostridium difficile. HAIs are an important metric for evaluating 
quality in health care institutions such that they are tracked by the Centers for Medicare and Medicaid Services (CMS) in its Hospital Compare program. ${ }^{2}$ High scores (poor performance) can lead to penalties, such as those associated with the Hospital-Acquired Condition Reduction Program established by the 2010 Patient Protection and Affordable Care Act; specifically, patients with certain infection types cannot have the diagnosis-related group for their hospital admission changed to a more complex code to obtain a greater reimbursement from CMS to cover the increased hospital costs associated with the infection. Consumerfocused hospital ratings may also consider HAI rates in their evaluations. With an increase in the prevalence of resistant organisms and incentives to discharge patients quickly while minimizing readmission rates, concerns about HAIs will likely continue to increase.

Despite an obvious public health mandate to minimize the occurrence and impact of HAIs, identifying the most cost-effective or even effective strategies to do so is a source of uncertainty. A number of strategies have been proposed, ranging from environmental controls and modifications, to changing physical contact (eg, avoiding handshaking), to educating patients and health care providers on hand hygiene techniques, to using biosensors to identify areas in need of disinfection. Invariably, hand hygiene is a part of any effort to control HAIs. Hand hygiene programs typically include multiple components, including the more obvious ones, like well-placed cleansers and sinks, and structural elements, such as compliance assessments and feedback mechanisms. ${ }^{3}$

Recently, in the US, there has been discussion about the merits of various over-the-counter antiseptics, ${ }^{4}$ including those used in health care settings, such as health care personnel hand washes and rubs, surgical hand scrubs and rubs, and patient preoperative and preinjection skin preparations.

Introducing new interventions to decrease HAIs has inherent costs. For example, replacing surfaces with nonconductive copper has been shown to be effective ${ }^{5}$ but likely requires a substantial initial capital investment. Costs may be distributed by replacing surfaces one floor or ward at a time, yet there is likely to be both cost and interruption to care. Other interventions, like adding reminders about handwashing and stronger messaging, may be less costly to implement but may require a steady stream of funding to maintain.

The research question underlying this paper is regarding the cost of not maintaining the status quo: what is the cost associated with removing an existing effective component of programs to avoid HAIs - the use of health care antiseptic products? The objective of this project is to estimate the incremental hospital costs associated with preventable illnesses that would no longer be prevented if certain health care antiseptics were to be eliminated. A total national estimate of the potential lost benefits from elimination of these products is based on a national number of cases of HAIs, assumptions about the proportion of all HAIs that are overall preventable, assumptions about the proportion of preventable HAIs that are associated with health care antiseptics, and the hospital costs for these illnesses (specific to each infection) obtained from the published literature. The end product of this effort is a spreadsheet model that incorporates various input parameters and can be used to test and explore potential outcomes of limiting health care antiseptic products. The model accounts for the sources of uncertainty in several ways - it provides a range of input values rather than a single base case and also allows the user to input alternative values should the available selections be inadequate.

\section{Methods}

The model is designed as a simple spreadsheet tool without a single set of default values; instead, a range of plausible input parameters based on the published literature is provided, from which a user can select preferred input values. Four basic types of information are required to populate the model: first, the number of cases of each type of HAI of interest; second, the proportion of all HAIs that are preventable; third, the proportion of preventable HAIs attributable to the use of health care antiseptics; and finally, the average hospital cost associated with each HAI. Essentially, the calculation starts with an estimate of the number of HAIs in the US in 2011 (the most recently published data), reduces that number to account for the proportion of infections that are considered unpreventable overall and those that are preventable through use of health care antiseptics, and then assigns corresponding hospital costs to each of the remaining HAI cases. The resulting total infection count and cost equals the annual national estimate of potentially lost benefits that would be expected to occur if health care antiseptic products were eliminated.

Literature searches focusing on clinical efficacy and hospital costs were conducted to identify published values for model input parameters using the National Library of Medicine's PubMed database. After PubMed searches, targeted searches of authors whose works are prominent in the field and government or quasi-government bodies that engage in documenting or improving the performance of health care systems (eg, Centers for Disease Control and Prevention, World Health Organization, and Agency for Healthcare Research and Quality) were also conducted. 
Reviews and meta-analyses were examined for evidence of original data relevant to this analysis. For both the clinical and economic searches, reference lists of identified papers were also reviewed for relevant literature.

For the clinical efficacy component of the search, designed to identify papers that could provide information on the number of HAIs, preventability of HAIs, and the proportion of prevention attributable to the use of health care antiseptics, initial search terms (Medical Subject Headings [MeSH], keywords, and text fields) including "handwash", "healthcare", "hospital", and "rate" were used to identify papers published in the previous 25 years in English with human subjects. Studies on the number of HAIs were limited to the US, but for identifying estimates of preventability and proportion attributable to health care antiseptic use, no country or region limitations were used, as it was determined that these should not be excluded a priori but rather reviewed on a case-by-case basis.

For the economic component of the search, search terms (MeSH, keywords, and text fields) included "healthcare", "hospital", "infection", "costs and cost analysis", and related subheadings suggested by PubMed; filters were applied to identify papers published in the previous 10 years in English with human subjects. A shorter time frame was selected than that for the clinical efficacy search to minimize variation in treatments and associated costs that could occur over a longer time frame. Papers on costs were limited to those providing estimates for the US. Studies were considered for this analysis if they presented hospital costs per case, rather than per household or total expenditures associated with an outbreak, and if they reported on a broad mix of patients. Costs were inflated to October 2015 US\$ using the Consumer Price Index for medical care published by the Bureau of Labor Statistics (series ID CUUR0000SAM).

Abstraction of the cost estimates was a multistep process. Most papers provided a high and low estimate, rather than a single point estimate or average. To be consistent with the model's approach of providing a range of estimates, an average of all the low estimates for each HAI and an average of all the high estimates for each HAI were estimated.
In this manner, the estimates in the model not only inherently reflect uncertainty in the literature but also benefit from some aggregation of the estimates available.

\section{Results}

\section{Specification of input parameters} Number of HAls

Three recent studies provide estimates of the number of HAIs annually observed in the US. ${ }^{1,6,7}$ The estimates from these papers are provided in Table 1 . These studies estimate the number of cases of various infections but do not attempt to link infections to specific causal organisms. The model similarly makes the simplifying assumption that the distribution of pathogens within and across HAIs is not relevant to the number of HAIs. This is necessary given the lack of data on the distribution of pathogens on a national level and the lack of detail on other input parameters (eg, prevention and costs) by pathogen. It is not unreasonable to think that there could be differences in the preventability of HAIs based on changes in the distribution of the causal organisms, if health care antiseptic products are more effective against some pathogens than others, and the costs of treating the same HAI caused by different pathogens could vary. However, none of these data are available and therefore the model does not allow for specification of pathogens.

\section{Proportion of HAls that are preventable}

There are various estimates in the literature for the proportion of HAIs that are preventable $;^{8-10}$ best practices, including hand hygiene and many other interventions, do not eliminate HAIs entirely. Cases that are not preventable are eliminated from this analysis at this stage of the calculations, as the use of health care antiseptics could not have an effect on these already-existing infections. For example, Umscheid et $\mathrm{al}^{10}$ estimate that only $65 \%-70 \%$ of CLABSIs and CAUTIs and $55 \%$ of cases of VAP and SSIs are preventable. In their comprehensive review of the impact of various interventions, Harbarth et al also found wide variation in the proportion of preventable infections across settings and patient types, but they suggest that $20 \%$ is a reasonable proportion of HAIs that

Table I Model inputs: number of HAl cases by type and source

\begin{tabular}{|c|c|c|c|c|c|c|c|}
\hline & All & VAP/HAP & SSI & GI & CAUTI & CLABSI & Other \\
\hline Scott ${ }^{7}$ & $1,737,125$ & 52,543 & 290,485 & 178,000 & 449,334 & 92,011 & 674,752 \\
\hline Magill et al' & 721,800 & 157,500 & 157,500 & 123,100 & 93,300 & 71,900 & I I8,500 \\
\hline Klevens et $\mathrm{al}^{6}$ & I,737,125 & 250,205 & 290,485 & $\begin{array}{l}\text { Not reported; } \\
\text { included in "other" }\end{array}$ & 561,667 & 248,678 & 386,090 \\
\hline
\end{tabular}

Abbreviations: $\mathrm{HAI}$, health care-associated infection; VAP, ventilator-associated pneumonia; HAP, hospital-acquired pneumonia; SSI, surgical site infection; GI, gastrointestinal infection; CAUTI, catheter-associated urinary tract infection; CLABSI, central line-associated bloodstream infection. 
are preventable. ${ }^{9}$ Based on the wide range of values in the literature, the model includes multiple options for the proportion of HAIs that are preventable $(20 \%, 35 \%, 50 \%$, and $70 \%)$. A prespecified common value can be applied to all infection types or prespecified individual values can be applied to each type of infection. Alternatively, the model can be customized by providing a common user-specified value to be applied to all infections or by providing individual user-specified values to be applied to each type of infection.

\section{Number of prevented cases attributable to health care antiseptics}

Multiple studies were considered in developing reasonable model inputs for attributable cases. ${ }^{11-16}$ The range of values provided in these studies was used in the model, rather than a point estimate (eg, the average of all values provided in the studies), for the reduction of cases associated with health care antiseptic use. As with other model inputs, the simplifying assumption that use of health care antiseptics would prevent cases of all types of HAIs equally, regardless of pathogen, was made. At this time, there are insufficient data to assign different patterns of prevention by pathogen. The model allows the user to choose between providing individual values for each HAI type in addition to the common value for all HAI types, and selecting from prespecified values. These prespecified values, $10 \%, 20 \%$, and $30 \%$, were not based on specific studies but are intended to reflect a conservative range of estimates in the literature.

\section{Costs for each HAl}

A number of reviews and summary papers were found during the clinical portion of the literature search that helped guide the search for primary data sources. For example, $\mathrm{Scott}^{7} \mathrm{pub}$ lished a national estimate of HAI counts that also estimated hospital costs in the US. To account for variation of cost estimates and methods in the reviewed literature, a range of costs for each type of HAI (inflated to October 2015 US\$) was used in the model. Table 2 shows these ranges and the studies from which they were obtained. Several studies identified in the search were excluded, because they aggregated infections rather than presenting the infections of interest separately, or included a very specific population (eg, only pediatric or only elderly) or a small set of surgical interventions or settings, or did not include the year in which costs were presented. After inflating cost values to October 2015 US\$, estimates were aggregated by infection by taking the average of available low and high estimates for each infection type.
Table 2 Model inputs: costs per case by HAl (low, high values)

\begin{tabular}{|c|c|c|}
\hline Condition & $\begin{array}{l}\text { Costs per case } \\
\text { (in October } \\
2015 \text { US\$) }\end{array}$ & Sources \\
\hline CAUTI & $1,022-1,167$ & Anderson et $\mathrm{al}^{30}, \mathrm{Scott}^{7}$ \\
\hline CLABSI & $8,379-37,807$ & Anderson et $\mathrm{a}^{30}$, Eber et $\mathrm{al}^{31}, \mathrm{Scott}^{7}$ \\
\hline GI & $8,531-11,749$ & Anderson et $\mathrm{al}^{30}, \mathrm{McGlone}$ et $\mathrm{a}^{32}$, Scott ${ }^{7}$ \\
\hline SSI & $14,572-40,688$ & Anderson et $\mathrm{al}^{133}$, Anderson et $\mathrm{al}^{30}$, Scott \\
\hline VAP/HAP & $19,475-44,204$ & Anderson et $\mathrm{a}^{30}$, Eber et $\mathrm{al}^{31}$, Scott ${ }^{7}$ \\
\hline
\end{tabular}

Abbreviations: $\mathrm{HAl}$, health care-associated infection CAUTI, catheter-associated urinary tract infection; CLABSI, central line-associated bloodstream infection; GI, gastrointestinal infection; SSI, surgical site infection; VAP, ventilator-associated pneumonia; HAP, hospital-acquired pneumonia.

As a sensitivity analysis for hospital costs, values from Zimlichman et al's meta-analysis ${ }^{17}$ were also considered and are presented in Table 3. Zimlichman et al's meta-analysis, while including papers from very small or specific populations that were rejected based on our inclusion criteria for hospital cost papers, is the most recent attempt to identify the economic impact of HAIs in the US, and therefore, its values have been included as a built-in sensitivity analysis.

\section{Model results}

The spreadsheet model developed for this analysis incorporates findings from the relevant literature as default input values, and it offers the ability to modify default values to reflect results from additional papers and trends, gauge uncertainties, and explore scenarios of interest.

A low and a high scenario are presented in this study to provide a range of health care expenditures currently being averted by the use of health care antiseptics. Table 4 shows the model inputs used for these two scenarios. The low ${ }^{1}$ and $\operatorname{high}^{7}$ scenarios selected here use national estimates for the HAIs from a single published paper (Magill et al ${ }^{1}$ for the low, $\mathrm{Scott}^{7}$ for the high) for consistency, although one could arrive at higher counts by using the number of gastrointestinal infections from one study and SSIs from another, for example.

Table 3 Model sensitivity analysis: costs per case by HAl (metaanalysis values)

\begin{tabular}{ll}
\hline Condition & $\begin{array}{l}\text { Costs per case } \\
\text { (in October 20I5 US\$) }\end{array}$ \\
\hline CAUTI & 962 \\
CLABSI & 49,201 \\
GI & 12,119 \\
SSI & 22,322 \\
VAP/HAP & 43,112 \\
\hline
\end{tabular}

Abbreviations: HAl, health care-associated infection; CAUTI, catheter-associated urinary tract infection; CLABSI, central line-associated bloodstream infection; GI, gastrointestinal infection; SSI, surgical site infection; VAP, ventilator-associated pneumonia; HAP, hospital-acquired pneumonia. 
Table 4 Low and high scenario input parameters

\begin{tabular}{|c|c|c|}
\hline Parameter & Low & High \\
\hline Number of HAIs, USA, annual & 721,800 & $\mathrm{I}, 737,125^{7}$ \\
\hline Proportion of HAls that are preventable (\%) & 20 & 70 \\
\hline $\begin{array}{l}\text { Proportion of HAI prevention attributable to } \\
\text { use of health care antiseptics (\%) }\end{array}$ & 10 & 30 \\
\hline \multirow{7}{*}{$\begin{array}{l}\text { use of health care antiseptics (\%) } \\
\text { Costs per HAI (US\$) }\end{array}$} & Average low estimate from & Average high estimate from \\
\hline & literature review: & literature review: \\
\hline & CAUTI: I,022 & CAUTI: I,I67 \\
\hline & CLABSI: 8,379 & CLABSI: 37,807 \\
\hline & GI: 8,531 & GI: II,749 \\
\hline & SSI: 14,572 & SSI: 40,688 \\
\hline & HAP/VAP: 19,475 & HAP/VAP: 44,204 \\
\hline
\end{tabular}

Abbreviations: HAI, health care-associated infection; CAUTI, catheter-associated urinary tract infection; CLABSI, central line-associated bloodstream infection; $\mathrm{GI}$, gastrointestinal infection; SSI, surgical site infection; VAP, ventilator-associated pneumonia; HAP, hospital-acquired pneumonia.

Based on the findings, the potential incremental hospital cost burden of hospital-acquired infections avoided by the use of health care antiseptics is between US\$142 million and US $\$ 4.25$ billion annually in the US. These results are presented in Table 5.

The results presented here provide a low and high estimate of the potential increase in cases and medical expenditures associated with elimination of health care antiseptic use. It is expected that actual potential increases would fall somewhere between these low and high estimates.

Given the uncertainty around many of the estimates in this model and our decision to use low and high estimates for model inputs rather than single values, traditional sensitivity analyses are not appropriate. Instead, we used values from Zimlichman et al's 2013 meta-analysis ${ }^{17}$ as a comparison for hospital costs (number of cases prevented was not compared). The estimated avoided costs based on Zimlichman et al's meta-analysis range from US $\$ 308$ million to US $\$ 3.33$ billion, which fall within the range of our model results. As with the low and high values discussed previously, the low end of this range is estimated using the number of current annual cases from Magill et $\mathrm{al}^{1}$ and the high end using the estimate from Scott. ${ }^{7}$

\section{Discussion}

The purpose of this model is to help guide decision-making in the face of uncertainty. The model is a representation of the complex real-world relationships among changing rates of infections, hospital costs, and the potential impact of health care antiseptics. In the face of uncertainty about the continued availability of health care antiseptics, the model reflects the current state of knowledge while providing the opportunity to explore a variety of scenarios. The low and high scenarios presented in this paper can be used to understand the potential economic impact of a change in availability of health care antiseptics on human health and hospital costs in the US. Though the findings estimated here cover a broad range due to the breadth of existing data used in the model, they are indicative of the potential impact of changes in availability of health care antiseptics at the national level. The range of

Table 5 Estimates of potential additional national economic burden

\begin{tabular}{|c|c|c|c|c|c|c|c|c|}
\hline \multirow[t]{2}{*}{ Condition } & \multicolumn{4}{|c|}{ Low estimates } & \multicolumn{4}{|c|}{ High estimates } \\
\hline & $\begin{array}{l}\text { Current } \\
\text { costs }\end{array}$ & $\begin{array}{l}\text { Number of } \\
\text { current cases }\end{array}$ & $\begin{array}{l}\text { Costs } \\
\text { prevented }\end{array}$ & $\begin{array}{l}\text { Number of } \\
\text { cases prevented }\end{array}$ & $\begin{array}{l}\text { Current } \\
\text { costs }\end{array}$ & $\begin{array}{l}\text { Number of } \\
\text { current cases }\end{array}$ & $\begin{array}{l}\text { Costs } \\
\text { prevented }\end{array}$ & $\begin{array}{l}\text { Number of } \\
\text { cases prevented }\end{array}$ \\
\hline CAUTI & $\$ 19 M$ & $93.3 \mathrm{~K}$ & $\$ 2 M$ & $1.9 \mathrm{~K}$ & $\$ 367 M$ & $449.3 \mathrm{~K}$ & \$IIOM & $94.4 \mathrm{~K}$ \\
\hline CLABSI & $\$ 120 M$ & $71.9 \mathrm{~K}$ & $\$ 12 M$ & $\mathrm{I} .4 \mathrm{~K}$ & $\$ 2,435 M$ & $92.0 \mathrm{~K}$ & $\$ 730 \mathrm{M}$ & $19.3 \mathrm{~K}$ \\
\hline GI & $\$ 210 M$ & I23.IK & $\$ 21 M$ & $2.5 \mathrm{~K}$ & $\$ 1,464 M$ & I78.0K & $\$ 439 M$ & $37.4 \mathrm{~K}$ \\
\hline SSI & $\$ 459 M$ & I57.5K & $\$ 46 \mathrm{M}$ & $3.2 \mathrm{~K}$ & $\$ 8,273 M$ & $290.5 \mathrm{~K}$ & $\$ 2,482 M$ & $61.0 \mathrm{~K}$ \\
\hline VAP/HAP & $\$ 613 M$ & $157.5 \mathrm{~K}$ & $\$ 61 M$ & $3.2 \mathrm{~K}$ & $\$ 1,626 \mathrm{M}$ & $52.5 \mathrm{~K}$ & $\$ 488 \mathrm{M}$ & II.0K \\
\hline Total & $\$ 1,422 M$ & $603.3 \mathrm{~K}$ & $\$ 142 M$ & $12.1 \mathrm{~K}$ & $\$ 14,165 M$ & $\mathrm{I}, 062.4 \mathrm{~K}$ & $\$ 4,250 M$ & $223.1 \mathrm{~K}$ \\
\hline
\end{tabular}

Notes: "Number of cases prevented" and "Costs prevented" refer to the cases and associated costs that are estimated to be currently prevented by the use of antiseptics, respectively. Totals may differ from the expected value due to rounding. As the number of cases in the low and high scenarios differs for each condition, the relationships between low and high estimates are influenced by factors other than the portion attributable and proportion associated with antiseptics and results are not linear.

Abbreviations: CAUTI, catheter-associated urinary tract infection; CLABSI, central line-associated bloodstream infection; GI, gastrointestinal infection; K, thousand; M, million; SSI, surgical site infection; VAP, ventilator-associated pneumonia; HAP, hospital-acquired pneumonia. 
estimates can be narrowed as new data become available for the model. In addition, the uncertainty in the model may be substantially minimized when applied to local, institutionor system-specific situations, since input data are generally better understood at the local level. Ideally, the model could be applied to explore the local impact of antiseptic availability to aid in decision-making, in addition to projecting values nationally.

There are multiple sources of uncertainty associated with the estimates used as model input parameters. We address how the model incorporates and manages this uncertainty across each of the four main model inputs in turn. First, there are challenges in identifying the total number of HAIs nationally. The studies selected for use in this model are based on reported infections as part of surveillance programs rather than administrative claims data to identify events. A recent review and meta-analysis of the accuracy of using administrative data to identify HAIs ${ }^{18}$ found inconsistencies across types of infections in terms of sensitivity and specificity. This, as well as earlier work that suggests "traditional" surveillance reporting is superior to other approaches for identifying HAIs, ${ }^{19}$ supports our avoidance of administrative claims data in the base case estimates but points to difficulties in quantifying the number of HAIs. The same surveillance reports suggest that rates of HAIs are higher among patient populations who are younger, older, or otherwise compromised, ${ }^{20}$ which both validates our decision not to include data from these studies and suggests that once these more severe patients are included, their higher hospital costs might mean our general population approach underestimates infections and costs. Additionally, the process of attribution on the part of the hospital is complex; determining whether an infection is health care-associated can be challenging, particularly for patients who have had multiple health care encounters prior to the hospital admission. The model is limited to infections that are treated in a hospital setting, but the problem of infections acquired in long-term care is known to be substantial. ${ }^{21}$ If it were possible to quantify the number and treatment costs for health care-associated infections in other settings, estimates of the national impact of HAIs would increase. Lastly, also related to the count of HAIs included in this model, the analysis was limited to bacterial infections only. However, health care antiseptics, particularly alcohol-based hand rubs and gels, may have a role in preventing viral conditions. ${ }^{22}$ Thus, the findings of this study could be considered to be conservative and benefits would increase if viral conditions were included in the model. At this point, there are insufficient data to add the estimates for viral infections to the model but future studies may permit it.

A second source of uncertainty is related to estimating the proportion of cases prevented by the use of health care antiseptics. This aspect of uncertainty is challenging because, in accordance with the World Health Organization guidelines, ${ }^{23}$ the use of health care antiseptics is only one component of typical multipart strategies to address hygiene. In their meta-analysis, Schweizer et al point out that more than three-fourths of interventions included bundles with multiple components rather than the single-intervention studies that have been observed in previous reviews (see Schweizer et al for a full listing of the studies reviewed). ${ }^{24}$ Rarely do studies report on a comparison between similar cohorts in which the use of health care antiseptics is the only difference. The effect of introduction or elimination of antiseptics alone is not addressed sufficiently in the literature for each of the infection types of interest. The model acknowledges this and is conservative in eliminating a number of infections that are deemed to be not preventable by any means and by assuming, in our high scenario, that no more than $30 \%$ of preventable infections could be prevented based on health care antiseptic use. The structure and form of the model are designed with the assumption that there is some effect of health care antiseptic use on the rate of HAIs, consistent with real-world findings, ${ }^{25,26}$ but it accepts the user's input about what fraction of HAIs can be prevented rather than endorsing a particular value. It would have been possible to split the prevention component of the model into two separate pieces, one of which would apply values for the potential preventive effect of the antiseptics, and the second of which would allow the user to assume the level of performance to moderate the potential effect. Given the uncertainty in these inputs as well as the fact that they would simply be multiplied, we chose to handle this issue as a single model input. Further, the model only estimates incremental hospital costs for infections that can reasonably be attributed to the use of hand hygiene rather than a more comprehensive set of benefits. Thus, the estimates here are likely to be conservative.

Third, there is uncertainty about the financial impact of HAIs, although a variety of methods and approaches have been used to develop estimates. The health care facilities and sites that were used for the estimates in the model may have had an older/younger or sicker/healthier population than an average hospital. In most cases, the model used an average of available cost estimates, which should minimize the influence of particular factors associated with an individual study or site on the final estimate used. Even if the cost for 
each type of HAI were known, it is important to recognize the difference between reimbursements, herein referred to as costs, and the actual costs that a hospital requires to treat a patient. Although insurers may not directly bear the costs for HAIs in the future given the trend toward not reimbursing hospitals for a growing list of preventable infections, hospitals will still need to provide the additional resources required to treat the infections.

The scope of this model includes only initial hospital costs associated with HAIs in the US. As such, the model inputs that required use of US data included the counts of HAIs and hospital costs. The model integrated data on preventive potential and attributability to antiseptics from any study worldwide, with the assumption that the preventive effect of any agent would be similar regardless of the region in which it was used. There are a number of additional costs relevant to calculating the full impact of removing antiseptic products from the market not captured here. These costs include but are not limited to hospital readmission, shortterm rehabilitation, long-term follow-up care, co-pays and out-of-pocket fees, lost wages, caregiver assistance, lost productivity, and transportation. General estimates for these elements are available in the published literature and could be combined with the HAI-specific inputs to this model to produce a more comprehensive evaluation of costs..$^{27,28} \mathrm{As}$ the costs of long-term morbidity and mortality are not currently included in this analysis, the model's estimates are conservative.

In addition to these sources of uncertainty, there is also a layer of regional variation that should be considered in applying these findings. Various hospitals, regions, and payers may have different input assumptions than those used in this model based on the pathogens present in their facilities. Certain pathogens, resistance patterns, and infection types are more prevalent at some facilities and in particular regions than others, and thus while this model is designed to reflect the US as a whole, results cannot directly be scaled down to reflect a smaller region or population.

Not only are there differences in terms of HAIs and causes across sites but there may also be differences in populations. HAIs may cause disproportionate burden in certain racial and ethnic groups. Findings from an analysis of the Medicare Patient Safety Monitoring System suggest that the rate of HAIs is significantly higher among Asian and Hispanic patients. ${ }^{29}$ Because there are insufficient data to add patient characteristics to the model, it has not been included; however, the inclination to scale these estimates to subpopulations should be resisted for this reason, also.
It is important to recognize that this analysis does not challenge the idea that some hospital-acquired infections are not preventable. Even in the low scenario (which uses the most conservative estimates), the model assumes that some HAIs cannot be prevented. However, the reported number of HAIs may be influenced by lack of reimbursement. In their efforts to minimize rates of HAIs, hospitals may conduct more screening at admission to understand whether patients are already colonized at admission to determine whether infections should be considered hospital-acquired, ${ }^{8}$ which could result in a decrease in infections determined to be hospitalacquired. Further, lack of reimbursement for some of these infections may encourage proactive antibiotic treatment and the unintended negative consequence of contributing to development of resistance, making HAIs more expensive to treat. Regardless of these uncertainties, the underlying framework of this model assumes that there is some proportion of HAIs that are currently avoided as a result of the use of health care antiseptics, and that limiting availability of these types of products would be associated with an increase in the rate of these types of infections and associated hospital costs.

\section{Conclusion}

Although multiple sources of uncertainty exist, this model uses a range of estimates to effectively identify the plausible effect of health care antiseptic use on the number of HAIs and associated hospital costs in the US. Low- and highend estimates of the number of national, annual HAI cases avoided through use of health care antiseptics are 12,100 and 223,000, respectively, with associated avoided hospital costs of US\$142 million and US\$4.25 billion, respectively.

\section{Author contributions}

JKS and CKH took primary responsibility for review of literature, JKS and SS took responsibility for model design and construction, and JAK, PCD, RS, and PAC provided inputs and interpretations. All authors contributed toward data analysis, drafting and revising the paper and agree to be accountable for all aspects of the work.

\section{Disclosure}

JK Schmier, CK Hulme-Lowe, S Semenova, and JA Klenk are employees of Exponent, a consulting company that has received a grant from the American Cleaning Institute for this research. PC DeLeo and R Sedlak are employees of the American Cleaning Institute. PA Carlson is an employee of Ecolab. The authors report no other conflicts of interest in this work. 


\section{References}

1. Magill SS, Edwards JR, Bamberg W, et al. Multistate pointprevalence survey of health care-associated infections. N Engl J Med. 2014;370(13):1198-1208.

2. Medicare.gov. Hospital Compare. Readmissions, complications, and deaths. Available from: http://www.medicare.gov/hospitalcompare/ about/rcd.html. Accessed June 5, 2015.

3. Ellingson K, Haas JP, Aiello AE, et al. Strategies to prevent healthcareassociated infections through hand hygiene. Infect Control Hosp Epidemiol. 2014;35(8):937-960.

4. Food and Drug Administration. Safety and Effectiveness for Health Care Antiseptics; Topical Antimicrobial Drug Products for Over-the-Counter Human Use; Proposed Amendment of the Tentative Final Monograph; Reopening of Administrative Record. Docket No. FDA-2015-N-0101. Preliminary Regulatory Impact Analysis. Initial Regulatory Flexibility Analysis. Unfunded Mandates Reform Act Analysis. Economics Staff OoP, Office of Policy, Planning, Legislation, and Analysis, Office of the Commissioner, Department of Health and Human Services. 2015. Available from http://www.fda.gov/downloads/AboutFDA/ReportsManualsForms/Reports/UCM447035.pdf. Accessed February 15, 2016.

5. Salgado CD, Sepkowitz KA, John JF, et al. Copper surfaces reduce the rate of healthcare-acquired infections in the intensive care unit. Infect Control Hosp Epidemiol. 2013;34(5):479-486.

6. Klevens RM, Edwards JR, Richards CL Jr, et al. Estimating health care-associated infections and deaths in U.S. hospitals, 2002. Public Health Rep. 2007;122(2):160-166.

7. Scott RD 2nd. The Direct Medical Costs of Healthcare-Associated Infections in U.S. Hospitals and the Benefits of Prevention. Division of Healthcare Quality Promotion; National Center for Preparedness D, and Control of Infectious Diseases; Coordinating Center for Infectious Diseases; Centers for Disease Control and Prevention. 2009. Available from http://www.cdc.gov/HAI/pdfs/hai/Scott_CostPaper.pdf. Accessed February 15, 2016.

8. Brown J, Doloresco Iii F, Mylotte JM. "Never events": not every hospital-acquired infection is preventable. Clin Infect Dis. 2009; 49(5):743-746.

9. Harbarth S, Sax H, Gastmeier P. The preventable proportion of nosocomial infections: an overview of published reports. $J$ Hosp Infect. 2003;54(4):258-266; quiz 321.

10. Umscheid CA, Mitchell MD, Doshi JA, Agarwal R, Williams K, Brennan PJ. Estimating the proportion of healthcare-associated infections that are reasonably preventable and the related mortality and costs. Infect Control Hosp Epidemiol. 2011;32(2):101-114.

11. Gordin FM, Schultz ME, Huber RA, Gill JA. Reduction in nosocomial transmission of drug-resistant bacteria after introduction of an alcohol-based handrub. Infect Control Hosp Epidemiol. 2005;26(7): 650-653.

12. Hayden MK, Bonten MJ, Blom DW, Lyle EA, van de Vijver DA, Weinstein RA. Reduction in acquisition of vancomycin-resistant enterococcus after enforcement of routine environmental cleaning measures. Clin Infect Dis. 2006;42(11):1552-1560.

13. Lai KK, Fontecchio S, Melvin Z, Baker SP. Impact of alcoholbased, waterless hand antiseptic on the incidence of infection and colonization with methicillin-resistant Staphylococcus aureus and vancomycin-resistant enterococci. Infect Control Hosp Epidemiol. 2006;27(10):1018-1024.

14. Harrington G, Watson K, Bailey M, et al. Reduction in hospitalwide incidence of infection or colonization with methicillin-resistant Staphylococcus aureus with use of antimicrobial hand-hygiene gel and statistical process control charts. Infect Control Hosp Epidemiol. 2007;28(7):837-844.
15. Pittet D, Hugonnet S, Harbarth S, et al. Effectiveness of a hospital-wide programme to improve compliance with hand hygiene. Infection Control Programme. Lancet. 2000;356(9238):1307-1312.

16. Zoabi M, Keness Y, Titler N, Bisharat N. Compliance of hospital staff with guidelines for the active surveillance of methicillin-resistant Staphylococcus aureus (MRSA) and its impact on rates of nosocomial MRSA bacteremia. Isr Med Assoc J. 2011;13(12):740-744.

17. Zimlichman E, Henderson D, Tamir O, et al. Health care-associated infections: a meta-analysis of costs and financial impact on the US health care system. JAMA Intern Med. 2013;173(22):2039-2046.

18. Goto M, Ohl ME, Schweizer ML, Perencevich EN. Accuracy of administrative code data for the surveillance of healthcare-associated infections: a systematic review and meta-analysis. Clin Infect Dis. 2014;58(5):688-696.

19. Stamm AM, Bettacchi CJ. A comparison of 3 metrics to identify health care-associated infections. Am J Infect Control. 2012;40(8):688-691.

20. Dudeck MA, Weiner LM, Allen-Bridson K, et al. National Healthcare Safety Network (NHSN) report, data summary for 2012, Deviceassociated module. Am J Infect Control. 2013;41(12):1148-1166.

21. Dwyer LL, Harris-Kojetin LD, Valverde RH, et al. Infections in longterm care populations in the United States. J Am Geriatr Soc. 2013; 61(3):342-349.

22. Larson EL, Cohen B, Baxter KA. Analysis of alcohol-based hand sanitizer delivery systems: efficacy of foam, gel, and wipes against influenza A (H1N1) virus on hands. Am J Infect Control. 2012;40(9): 806-809.

23. World Health Organization. WHO Guidelines on Hand Hygiene in Health Care: First Global Patient Safety Challenge. Clean Care Is Safer Care. Geneva, Switzerland: World Health Organization; 2009.

24. Schweizer ML, Reisinger HS, Ohl M, et al. Searching for an optimal hand hygiene bundle: a meta-analysis. Clin Infect Dis. 2014;58(2):248-259.

25. Ben-David D, Masarwa S, Adler A, Mishali H, CarmeliY, Schwaber MJ. A national intervention to prevent the spread of carbapenem-resistant Enterobacteriaceae in Israeli post-acute care hospitals. Infect Control Hosp Epidemiol. 2014;35(7):802-809.

26. Schweon SJ, Edmonds SL, Kirk J, Rowland DY, Acosta C. Effectiveness of a comprehensive hand hygiene program for reduction of infection rates in a long-term care facility. Am J Infect Control. 2013; 41(1):39-44.

27. Davis K, Collins SR, Doty MM, Ho A, Holmgren AL. Health and productivity among U.S. workers. Issue Brief (Commonw Fund); $2005 ;(856): 1-10$.

28. Lawrence BA, Bhattacharya S, Zaloshnja E, et al. Medical and Work Loss Cost Estimation Methods for the WISQARS Cost of Injury Module. Calverton, MD: Pacific Institute for Research and Evaluation; 2011.

29. Bakullari A, Metersky ML, Wang Y, et al. Racial and ethnic disparities in healthcare-associated infections in the United States, 2009-2011. Infect Control Hosp Epidemiol. 2014;35(Supp1 3):S10-S16.

30. Anderson DJ, Pyatt DG, Weber DJ, Rutala WA; North Carolina Department of Public Health HAIAG. Statewide costs of health care-associated infections: estimates for acute care hospitals in North Carolina. Am J Infect Control. 2013;41(9):764-768.

31. Eber MR, Laxminarayan R, Perencevich EN, Malani A. Clinical and economic outcomes attributable to health care-associated sepsis and pneumonia. Arch Intern Med. 2010;170(4):347-353.

32. McGlone SM, Bailey RR, Zimmer SM, et al. The economic burden of Clostridium difficile. Clin Microbiol Infect. 2012;18(3):282-289.

33. Anderson DJ, Kaye KS, Chen LF, et al. Clinical and financial outcomes due to methicillin resistant Staphylococcus aureus surgical site infection: a multi-center matched outcomes study. PLoS One. 2009;4(12):e8305. 


\section{Publish your work in this journal}

ClinicoEconomics \& Outcomes Research is an international, peerreviewed open-access journal focusing on Health Technology Assessment, Pharmacoeconomics and Outcomes Research in the areas of diagnosis, medical devices, and clinical, surgical and pharmacological intervention. The economic impact of health policy and health systems organization also constitute important areas of coverage. The manuscript management system is completely online and includes a very quick and fair peer-review system, which is all easy to use. Visit http://www.dovepress.com/testimonials.php to read real quotes from published authors.

Submit your manuscript here: http://www.dovepress.com/clinicoeconomics-and-outcomes-research-journal 